Yashraj Jain

is Senior Research Executive at the Direct Marketing Association UK. The DMA seeks to lead the way for one-to-one marketing and to help the industry do better business.

Raka Garg

is a market research consultant and Director of Business Intelligence at medeuronet, leading the digital content strategy for a new digital portal for medical technology innovations in Europe.

Keywords: email marketing, strategy, DMA, email benchmarking

\section{Improving return on investment}

\section{New focus on outcomes}

\section{Better click-through and delivery \\ Yashraj Jain \\ The Direct Marketing Association DMA House, 70 Margaret Street, London, W1W 8SS, UK \\ Tel: 0207291330 \\ E-mail: yashraj.jain@dma.org.uk}

\section{Business Intelligence}

\section{National email benchmarking report 2013}

\author{
Yashraj Jain and Raka Garg \\ Received (in revised form): 27th October 2014
}

\begin{abstract}
The DMA collects data on email marketing campaigns from email service providers to gain an insight into trends and usage types. This article looks at some of the key findings from the report, covering strategic intention, personalization and segmentation.

Journal of Direct, Data and Digital Marketing Practice (2014) 16, 92-97. doi:10.1057/dddmp.2014.64
\end{abstract}

\section{Overview}

Email marketing continues to deliver strong performance. It is used by over 90 per cent of businesses and provides a cost efficient and powerful channel for both broadcasting news and one-to-one communications. Among the growing list of techniques and disciplines available to marketers, email marketing stands tall as the best channel for delivering a return on investment (ROI). ${ }^{1}$ ROI on email marketing investment reached $25: 1$ in 2013 , up from $£ 21.5$ per $£ 1$ invested in 2012 . $^{2}$

Email strategy in 2013 reflects a focus on improving outcomes, namely, ROI and overall productivity. This was manifested in different ways, such as:

- better segmentation and targeting, rather than growing volume of emails;

- improving quality of customer databases, rather than growing customer lists;

- personalizing emails with behaviour-driven dynamic content, rather than growing volume broadcast emails.

Thus, email marketers are recognizing and leveraging the trend towards mobile and consumer appetite for personalization.

Tangible gains from the changes were reflected in improvements in total click-through rates, lower default bounce thresholds and lowest-ever hard bounce rates. The gains may not have been significant enough to be reflected in all the quantitative metrics. However, a mental shift is the first imperative for a strategic orientation in practice. To quote one of the email service provider (ESP) participants, 'email marketers need to adopt a strategy to develop long term campaigns ...' . 


\section{Short-term view dominates}

One final point for consideration is measuring and benchmarking email performance. Greater investment in analytics, as well as acting on data to improve performance, is emerging as a high priority for email marketers. $^{3}$

\section{Strategic versus tactical uses of email}

Email marketing still seems to be implemented in a more tactical mode by most marketers relative to a strategic approach used by a few email marketers. These two modes were defined as follows:

Strategic: Any actions involving long-term decisions or plans designed to impact favourably on the overall effect of email marketing.

Tactical: Any actions that are immediate or short term in duration.

Too many marketers fall into the trap that 'email is cheap' and neglect to think through their entire strategy. A good campaign should be well planned, and should include test parameters, analysis and refinement ${ }^{4}$ (Figure 1).

\section{Changes in email strategy}

Email strategy in 2013 was strongly focused on financial returns, namely, increasing overall contribution and ROI in the face of anticipated decline in budgets (see Figure 2). There was greater attention to segmentation and targeting, rather than increasing overall number of emails or growing the list size. Other industry reports corroborate this shift in focus from growing list size to improving the quality of databases. In the past, there was substantial investment in growing list size and therefore email marketers now have large customer databases. Email lists are still growing, albeit slowly, ${ }^{3}$ while 60 per cent of marketers admit that their biggest barrier to effective email marketing is the quality of their email database the foundation upon which segmentation and automation rests. ${ }^{1}$

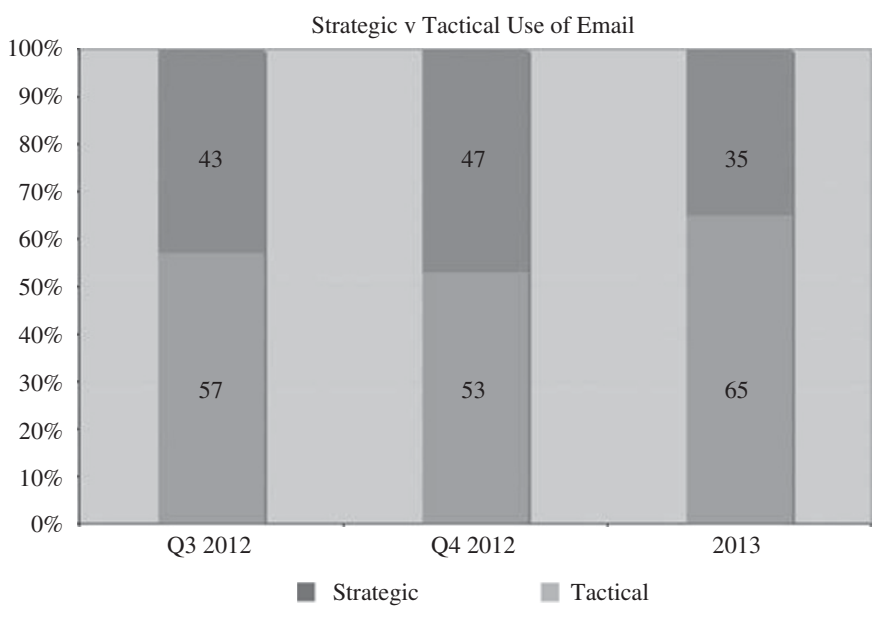

Figure 1: Strategic versus tactical uses of email 


\section{Focus on consumer needs}

\section{Value as well as function}

\section{Beyond the subject line}

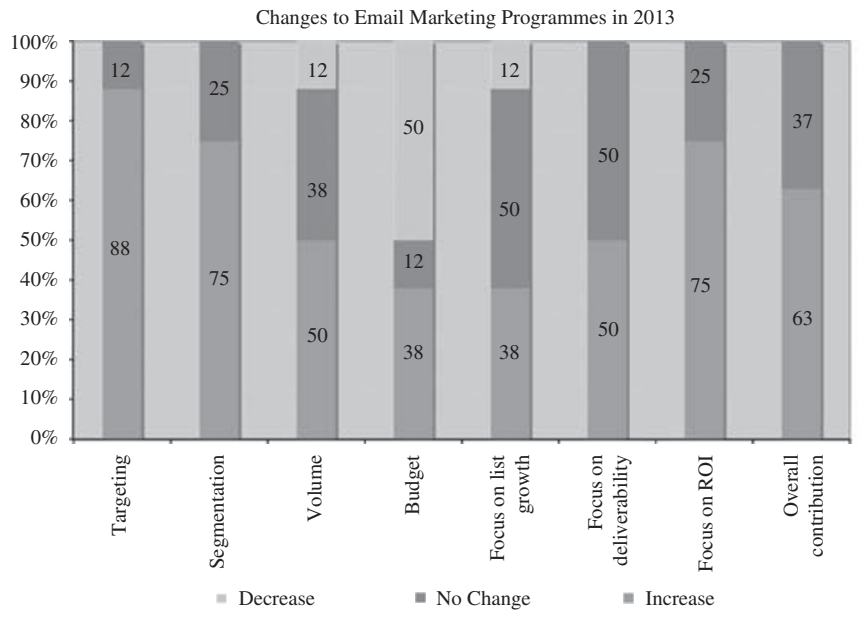

Figure 2: Changes in email marketing programmes in 2013

\section{Personalization}

Recent research from Econsultancy/Adestra ${ }^{5}$ found that 52 per cent of digital marketers agree that 'the ability to personalize content is fundamental to their online strategy'. When it comes to email, personalization is of even greater importance. A recent study by Yahoo! finds not only that most consumers are aware of online personalization, but that they believe that it provides added relevance, with 78 per cent of those surveyed expressing a desire for some type of personalized content. ${ }^{6}$ Despite all the opportunities for increased personalization today, it is important not to personalize for personalization's sake, or to become fixated on the latest tools or techniques, but to be sure you are using it to address a consumer-relevant need. $^{7}$

Mark Brownlow offers useful insights in this context. Personalized, behaviour-based and trigger emails can help ensure that email marketing is functionally very successful. However, the recipient is not an entry in a database but a human who wants some kind of 'value' in return for the time they spend on our emails. This value can indeed be functional (a great deal, insightful article, good advice). But they also value personality engaging writing, creativity, humour, sometimes giving value and asking for nothing in return. These are all the things that help distinguish you from the competition when they are also offering a ' 15 per cent off everything sale'. ${ }^{8}$

In this study, dynamic content and custom fields were cited as the personalization functions used most often. Behaviour-driven content was cited as the third most frequently used approach to personalization (compared with not being cited at all in 2012). This is consistent with the continuing dominance of retention emails, which made up 68 per cent of all emails in Q4 2013. These findings also demonstrate that email marketers are going beyond front-end personalization (name and subject line) to enhance the shopping experience with the use of behaviour-driven dynamic content (see Table 1). 
Table 1: Personalization techniques used by ranking

\begin{tabular}{ll}
\hline 1 & Dynamic content \\
2 & Multiple custom fields \\
3 & Behaviour-driven content \\
4 & Conditional text \\
5 & Predictive content \\
\hline
\end{tabular}

\section{Growth in differentiation}

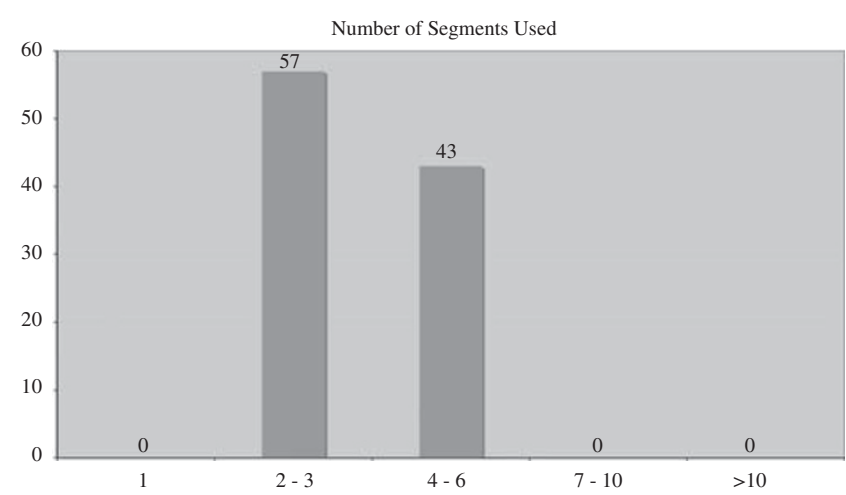

Figure 3: Number of segments used in campaigns

\section{Segmentation}

In this study, 57 per cent of campaigns had two to three different segments and the balance had four to six different segments (see Figure 3). It is encouraging to note that there were no single-segment campaigns, or any campaigns with too many segments (i.e. more than six segments). This seems to be in tandem with the downward trend in single-segment/ undifferentiated campaigns observed in the previous year's DMA National Email Benchmarking Report. In 2012, the first quarter started with 27 per cent of campaigns being single-segment and ended with only 8 per cent campaigns being single-segment in Q4. More focused segmentation and targeting was also reported as the key driver of increased ROI and overall success of email programmes in the National Client Email Marketing 2014 report.

Among marketers who have built campaigns incorporating advanced segmentation, 33 per cent of them would rate their email ROI as 'excellent' as opposed to just 13 per cent of those not doing it.'

\section{Focus for clients}

ESPs participating in this study perceive that clients are focusing more on creative and content, production, development and delivery, mobile optimization, and so on, and less on email strategy and related strategic dimensions such as customization, integration and web analytics (see Figure 4). The focus on mobile optimization and creative is understandable, given that more than half the emails are now opened on 
More strategic focus required

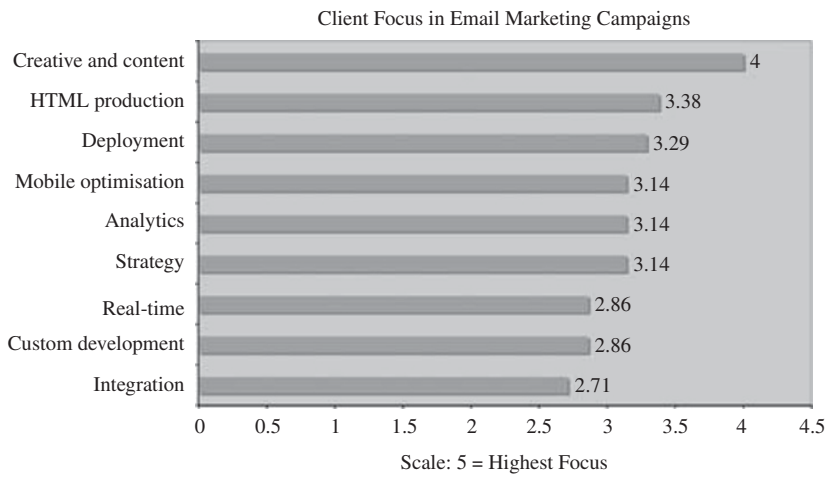

Figure 4: Areas of focus in email marketing

mobile devices and marketers and producers are still gearing up to align their creative email formats with this rapid change in consumer behaviour.

\section{Strategies to improve email marketing}

ESPs surveyed in this study offered some interesting insights and recommendations for what clients should do more of in their email marketing campaigns. A few are cited below:

\section{Strategy}

- Take a more strategic interest in email marketing, rather than leave it to the intern.

- Adopt a strategy to develop a long-term campaign with trigger campaigns.

- Focus more across channels and look at implementing larger, more progressive campaigns that make use of all customer touchpoints and not just business unit key performance indicator-focused activity.

- Focus on database and single customer view and integrating email into it.

- Re-engage with inactive subscribers.

\section{Analytics}

- Use analytics to measure and adopt strategies and campaigns in response to those metrics in an agile manner.

- Maintain a structured test-and-learn approach to existing programmes to improve performance.

- Focus on campaign results.

- Have set key performance indicators to measure success and failure.

The ESP sentiment about excessive client focus on creative and content is shared by email experts like Brownlow: 'Companies are continuing to spend the majority of a typical campaign on the creative aspect, in a pattern that remains fairly unchanged over the past six years' ${ }^{8}$ As marketers get 
more comfortable with the tools and technology of email marketing, a strategic, long-term approach to email marketing would be an important step forward. Top performers (in the United States) spend more than three times as much per month on email strategy than average performers. ${ }^{8}$

\section{Methodology}

The DMA National Email Benchmarking Report collects quantitative and qualitative data from ESPs who collectively deliver over 75 per cent of marketing emails in the United Kingdom. Data is aggregated and published at top-line level only to protect the identity and confidentiality of the ESPs and their clients. Data collection is carried out by Business Bound, the project is managed by the DMA research department and the report is written by Raka Garg on behalf of the Research Hub of the DMA Email Council. The DMA National Email Benchmarking Report 2013 was sponsored by Alchemy Worx.

\section{References and Notes}

1. Econsultancy/Adestra. (2014) Email Marketing Industry Census 2014, http://www.adestra.com/ resources/downloadable-reports/2014-email-marketing-industry-census/.

2. DMA. (2014) National Email Client Report 2014, http://www.dma.org.uk/research/nationalclient-email-report-2014.

3. Marketing Sherpa. (2013) Marketing Analytics Benchmarking Report, https://www. marketingsherpa.com/data/public/reports/benchmark-reports/EXCERPT-BMR-2013-MarketingAnalytics.pdf.

4. Epsilon. (2012) Acquisition email strategies in life beyond house-file marketing, http://www. emailinstitute.com/premium/acquisition-email-strategies-life-beyond-housefile-marketing.

5. Econsultancy/Adestra. (2012) Personalisation, Trust \& ROI, 2012, https://econsultancy.com/ reports/quarterly-digital-intelligence-briefing-personalisation-trust-and-roi.

6. Yahoo! (2014) The balancing act: Getting personalisation right, https://advertising.yahoo.com/ Insights/BALANCING-ACT.html.

7. The Guardian. (2014) Lucy Fisher "Personalisation in marketing: How far should brands go?", http://www.theguardian.com/media-network/media-network-blog/2014/jul/23/personalisationmarketing-online-brands.

8. Marketo. (2014) Mark Brownlow “Thought leadership snapshot”, http://www.marketo.com/ _assets/uploads/The-new-metrics-for-email-marketing.pdf?20130904180220.

9. Econsultancy/Adobe. (2014) Digital Trends 2014, http://success.adobe.com/en/UK/programs/ products/digitalmarketing/1401-30364-econsultancy-digital-trends.html. 